\title{
Erratum zu: Steharbeitsplätze mit Lasthandhabung: Einfluss des Belastungswechsels auf Muskelbeanspruchung, Beschwerdeempfinden und Beinvolumenänderung
}

\author{
Christiane Kamusella ${ }^{1}$ Martin Schmauder ${ }^{1}$ \\ Online publiziert: 16 . Oktober 2018 \\ (c) Springer-Verlag GmbH Deutschland, ein Teil von Springer Nature 2018
}

\section{Erratum zu:}

Z. Arb. Wiss.

https://doi.org/10.1007/s41449-018-0120-0

Leider fehlt in der am 5. Oktober 2018 online first veröffentlichten Originalversion des Beitrages die folgende Danksagung:

„An dieser Stelle wird Herrn Robert Seibt gedankt, der im Rahmen einer Kooperationsvereinbarung zur wissenschaftlichen Zusammenarbeit mit dem Universitätsklinikum Tübingen, Institut für Arbeitsmedizin, Sozialmedizin und Versorgungsforschung Hinweise gegeben hat."

Die Online-Version des Originalartikels ist unter https://doi.org/ 10.1007/s41449-018-0120-0 zu finden.

Dr. Ing. Christiane Kamusella

Christiane.Kamusella@tu-dresden.de

1 Professur für Arbeitswissenschaft, Institut für Technische Logistik und Arbeitssysteme, Fakultät Maschinenwesen, Technische Universität Dresden, 01062 Dresden, Deutschland 